
\title{
25 Research Soure \\ Effects of cordycepin, gold nanostar and their combination on endometrial cancer cells
}

Pedro Fong ( $\square$ pedrofong@ipm.edu.mo)

Macao Polytechnic Institute https://orcid.org/0000-0001-6426-3422

Chicheng Cheong

Macao Polytechnic Institute

Kawai Mak

Macao Polytechnic Institute Gaming Teaching and Research Center

Chicheng Lei

Macao Polytechnic Institute

Manhei Ho

Macao Polytechnic Institute

Chengngok Ao

Macao Polytechnic Institute

Lirong Meng

Macao Polytechnic Institute

\section{Research article}

Keywords: Au NS, Cordycepin, Endometrial cancer, Gold nanostar, HEC-1A

Posted Date: August 14th, 2019

DOI: https://doi.org/10.21203/rs.2.12813/v1

License: @ (i) This work is licensed under a Creative Commons Attribution 4.0 International License.

Read Full License

Version of Record: A version of this preprint was published at Natural Product Communications on August 1st, 2020. See the published version at https://doi.org/10.1177/1934578X20946939. 


\section{Abstract}

Background: The incidence rate of endometrial cancer has increased significantly in the past two decades. The current chemotherapy of endometrial cancer can cause intolerable side effects. Recently, both cordycepin and gold nanostars have demonstrated the ability to inhibit the growth and differentiation of cancers. The aim of this study was to investigate the anti-endometrial cancer effects of cordycepin, gold nanostars and the combination of two. Methods: The gold nanostars were made by seed-mediated reduction, and their morphology was confirmed by laser particle size analysis, spectrophotometry and electron microscopy. MTT cytotoxicity assays, clonogenic assays and flow cytometry were employed to evaluate the inhibition rate, survival fraction and apoptosis in HEC-1A cells under different concentrations of cordycepin, Au NS and their combination. Results: This study revealed that both cordycepin and Au NS with $808 \mathrm{~nm}$ light exposure could inhibit cell proliferation, cause cell apoptosis, and inhibit clone ability of endometrial cancer cells. The combined Au NS-cordycepin solution produced greater anti-cancer effects than each treatment alone. Conclusion: This study supports further investigations into Au NS-cordycepin in the development of new treatments for endometrial cancer.

\section{Background}

Endometrial cancer (EC) is one of the most common gynaecological epithelial malignancies [1]. Although the actual cause of the disease is unknown, it is generally believed that oestrogen plays an important role in the development of the disease. Common treatments for EC are surgical resection, radiation therapy, chemotherapy and hormonal therapy [2]. Approximately two-thirds of diagnosed EC patients are treated with surgical resection, which helps to reduce EC complications and the use of painkillers and also prolongs life [3]. However, the consequences of surgical resection are infertility and osteoporosis. Radiotherapy combined with chemotherapy is often used as the treatment of choice for mild to moderate states of cancer. The most common physiological side effects caused by these treatments include loss of appetite, fatigue, nausea, constipation, paralysis, insomnia, pain, hair loss, etc. Certainly, these side effects have a great impact on patient quality of life. Novel treatments are thus required to replace chemotherapy or to reduce the required dose.

Herbal medicines have played a significant role in cancer treatment, as some of them can enhance the efficacy and reduce the side effects of radiotherapy and chemotherapy [4]. Some can inhibit tumour progression, reduce surgical complications and increase the sensitivity of chemotherapeutic agents [5]. For example, cordycepin is an active component of Cordyceps sinensis, which has been found to have anti-cancer properties against varies types of cancer, including gynaecological malignancies, such as cervical and endometrial cancer [6]. Cordycepin is an adenosine receptor agonist, which can inhibit the synthesis of nucleic acids and promote the induction of apoptosis or autophagy in cancer cells [7]. Studies have shown that cordycepin inhibits polyadenylation, affects $\mathrm{G} 2 / \mathrm{M}$ phase cell cycle progression and prevents protein synthesis [8]. However, cordycepin tends to be metabolised rapidly by adenosine deaminase in animals and humans. This leads to an unfavourable short half-life of cordycepin and limited clinical usage [9]. One of the methods to overcome this unfavourable pharmacokinetic problem is 
to cover cordycepin in an appropriate dosage form, such as the gold nanostar system, which may help to reduce metabolism and effectively deliver cordycepin to its therapeutic site.

Gold nanostars (Au NS) are a genus of particles with a structure of about 50-80 nm in size and with a 'star-like' appearance [10]. It has been demonstrated that these particles have dual actions on cancer cells by producing photothermal effects and acting as a carrier to deliver chemotherapeutic agents into cells. A recently study demonstrated an acceptable $17 \%$ drug loading capacity of the anticancer drug doxorubicin and highlighted its good biocompatibility [11]. Another study conjugated cyclic RGD (CRGD) and doxorubicin with Au NS to build a multi-functional photothermal and chemotherapy system [12]. The study found promising anti-tumour efficiency against both a breast cancer cell line and in mice. These studies inspired us to investigate the potential of conjugating Au NS with cordycepin to inhibit the growth of endometrial cancer cells.

\section{Methods}

Au NS particles were prepared by a seed-mediated reduction method. The morphology and size distribution of the particles were analysed by a laser particle size analyser, a spectrophotometer and a transmission electron microscope (TEM). The uptake of Au NS by the endometrial cancer cell line (HEC$1 \mathrm{~A})$ at different temperatures was observed by spectrophotometry and using an inverted microscope. Cytotoxicity tests and apoptosis experiments were then carried out by MTT assays and flow cytometry, respectively, to analyse the effects of Au NS, cordycepin and their combination on HEC-1A cells.

\section{Preparation of Au NS}

Au NS was prepared by seed-mediated reduction [13]. A tetrachloroauric acid solution with a concentration of $1 \mathrm{mmol}$ was prepared using $0.08494 \mathrm{~g}$ of tetrachloroauric acid $\left(\mathrm{HAuCl}_{4}\right)$ and $250 \mathrm{ml}$ of deionised water. The solution was heated for 40 minutes. Then, $4.5 \mathrm{ml}$ of freshly prepared $1 \%$ sodium citrate solution was added to $30 \mathrm{ml}$ of the tetrachloroauric acid solution, followed by another 15 minutes of heating and vigorous stirring. The solution was allowed to cool and filtered through a $0.22 \mu \mathrm{m}$ filter membrane, which was used as the seed. The hydrodynamic size and polydispersity of the particles in the seed solution were measured using a laser particle size analyser (ZETASIZER Nano series, Malvern).

Stock solutions of $1 \mathrm{mmol}$ hydrochloric acid solution, $4 \mathrm{mmol}$ silver nitrate solution, $100 \mathrm{mmol}$ ascorbic acid solution and $0.25 \mathrm{mmol}$ tetrachloroauric acid solution were prepared. Next, $10 \mu \mathrm{l}$ of $1 \mathrm{mmol}$ hydrochloric acid solution was mixed with $10 \mu \mathrm{l}$ of $1 \mathrm{mmol}$ hydrochloric acid solution at $700 \mathrm{rpm}$. After 30 seconds, $100 \mu \mathrm{l}$ of the seed solutions was added to the mixture. After another 30 seconds, $100 \mu \mathrm{l}$ of a $4 \mathrm{mmol}$ silver nitrate solution and $50 \mu \mathrm{l}$ of a $100 \mathrm{mmol}$ ascorbic acid solution were also added. After centrifugation at $5000 \mathrm{rpm}$ for 15 minutes, the precipitate was removed and resuspended in $1 \mathrm{ml}$ of deionised water. Finally, the concentration of the Au NS solution was determined by the extinction coefficient and the Beer-Lambert law.

\section{Morphology and size}


The morphology of the Au-NS particles was observed by TEM (FEI Tale, 200keV) and the localised surface plasmon resonance (LSPR) was measured by UV-visible spectrophotometry (SPECTROstar Nano). The highest absorption peak of LSPR in this study was 800-850 nm [14]. The laser particle size analyser (ZETASIZER Nano series) were used to measure the particle sizes, aiming for a diameter between 50 and $80 \mathrm{~nm}$ [10]; the gold nanostar morphology was observed by TEM.

\section{Photothermal effect of Au NS and its conjugates}

Different concentrations of Au NS alone and Au NS-cordycepin solutions were cultured with Hec-1A cells for 24 hours. The supernatant was removed and the cells were washed three times with phosphate buffered saline (PBS). The temperature change induced by each concentration (Fig. 2) was detected after 10 minutes of $808 \mathrm{~nm}$ light exposure using an infrared temperature detector (Fluke Ti400). The experiments were repeated three times and the temperature changes of the cell culture medium was used as the control.

\section{Detection of Au NS uptake by ultraviolet-visible spectrophotometer}

Different concentrations of Au NS alone and Au NS-cordycepin solutions were cultured with HEC-1A cells for 24 hours. Two hundred grams of the cell suspension was centrifuged for 3 minutes and the cells were washed three times. The supernatant was collected for absorbance measurements by spectrophotometry at $808 \mathrm{~nm}$. The experiments were repeated three times and the absorbance of the cell culture medium was used as the control. The optical density (OD) was calculated using the following formula: $O D=$ (Mean absorbance of test group - Mean absorbance of medium control group) / (Mean absorbance of untreated group - Mean absorbance of medium control group).

\section{Cell culture}

The HEC-1A cell line (ATCC, Manassas, VA, USA) was cultured in RPMI-1640 (Gibco, 11875, Waltham, MA, USA) supplemented with $10 \%$ foetal bovine serum (Gibco, 16000044, Waltham, MA, USA). Cells were incubated at $37^{\circ} \mathrm{C}$ in a humidified $5 \% \mathrm{CO}_{2}$ atmosphere.

\section{Cytotoxic assay}

MTT (tetrazolium) assays were used to quantitatively evaluate the effect of Au NS, cordycepin and their combination on HEC-1A cells. The concentrations of Au NS were $3 \times 10^{10}$ particles $/ \mathrm{ml}, 6 \times 10^{10}$ particles $/ \mathrm{ml}$ and $1.2 \times 10^{11}$ particles $/ \mathrm{ml}$; the concentrations of cordycepin were $0.05 \mathrm{mg} / \mathrm{ml}, 0.1 \mathrm{mg} / \mathrm{ml}, 0.2 \mathrm{mg} / \mathrm{ml}$ and $0.4 \mathrm{mg} / \mathrm{ml}$. The concentration of the Au NS-cordycepin mixtures were $6 \times 10^{10}$ particles $/ \mathrm{ml}$ (AU Ns) +0.05 $\mathrm{mg} / \mathrm{ml}$ (cordycepin) and $3 \times 10^{10}$ particles $/ \mathrm{ml}$ (AU Ns) $+0.1 \mathrm{mg} / \mathrm{ml}$ (cordycepin). The HEC-1A cells were cultured in a 96-well plate and the exposure time for all samples was 24 hours. PBS was used to wash the cells and $120 \mu \mathrm{l}$ of MTT solution was added. The mixtures were incubated at $37^{\circ} \mathrm{C}$ and in a humidified $5 \% \mathrm{CO}_{2}$ atmosphere. After another 4 hours of incubation, $150 \mu \mathrm{l}$ of DMSO (Sigma-Aldrich, D4540, Burlington, MA, USA) was added to each well to dissolve the formazan crystals. The plates were gently 
shaken for 15 minutes at room temperature. The optical density (OD) of the solution was then measured using a microplate reader (SPECTROstar Nano, Ortenberg, Allmendgrün, Germany) at $550 \mathrm{~nm}$. The inhibition percentage was calculated as follows [15]:

Percentage viability $=100 \% \times$ mean of test OD / mean of control OD

Percentage inhibition $=100-$ percentage viability

\section{Clonogenic survival assay}

Clonogenic assays (CA) were performed to determine the division ability of HEC-1A cells, and hence, to determine the ability of Au NS and cordycepin to inhibit the growth of HEC-1A cells. Two hundred Hec-1A cells were seeded in a 48 -well plate for 24 hours in a humidified $5 \% \mathrm{CO}_{2}$ atmosphere at $37^{\circ} \mathrm{C}$. Cordycepin, Au NS and the combinations were added to the cells and left for 24 hours. The culture medium was then substituted with complete medium and cells were incubated for 7 days. Wright-Giemsa staining (Sigma, WG16) was used to stain the cell colonies, and those with 50 cells or more were counted. The plating efficiency (PE) and survival fraction (SF) were used to determine the ability of the HEC-1A cells to grow into colonies. This was calculated by the following equations [16]:

Plating efficiency $(P E)=($ No. of colonies formed $/$ No. of cells seeded $) \times 100 \%$

Survival fraction $(\mathrm{SF})=$ No. of colonies form $/$ (No. of cells seeded $\times$ PE)

\section{Apoptosis assessment}

Annexin V-FITC/PI staining was performed to detect apoptosis. Two millilitres of $1.0 \times 10^{5} \mathrm{HEC}-1 \mathrm{~A}$ cells $/ \mathrm{ml}$ were inoculated in $35-\mathrm{mm}$ culture dishes and incubated for 24 hours at $37^{\circ} \mathrm{C}$, with $5 \% \mathrm{CO}_{2}$ and $95 \%$ humidity. The cell supernatants were then collected and $1 \mathrm{ml}$ of each experimental solution was added to the dishes and incubated at $37^{\circ} \mathrm{C}$, with $5 \% \mathrm{CO}_{2}$ and $95 \%$ humidity. After 24 hours, the cells were harvested and resuspended using $100 \mu \mathrm{l}$ of the binding buffer provided with the apoptosis kit (BD Biosciences, 556547, San Diego, CA, USA). The suspension was stained by adding $5 \mu$ l of Annexin V-FITC and $5 \mu$ l of propidium iodide (PI) (Sigma-Aldrich, P4170, Burlington, MA, USA) for 15 minutes in the dark, followed by adding $400 \mu \mathrm{l}$ of binding buffer for the analysis of apoptosis using an Applied Biosystems Attune flow cytometer (Waltham, MA, USA) and the manufacturer's software.

\section{Statistical analysis}

Microsoft Office Excel 2013 and Statistical Product and Service Solutions (SPSS) software, version 24.0 were used to analyse all the results. Data are presented as the mean \pm the standard deviation (SD). A twotailed t-test was used to calculate the $P$ values of the differences between two groups of the cytotoxic assay and apoptosis assay while one-way analysis of variance multiple comparisons (one-way ANOVA) was used for the differences between three or more groups. If the $p$-value was smaller than 0.01 , it was considered to be statistically significant. 


\section{Results}

\section{Morphology and size}

TEM and the laser particle size analyser were employed to measure the size distribution of nanoparticles in solution. The highest absorption peak of Au NS was at 800-850 nm. The Au NS had an average diameter of $59.3 \mathrm{~nm}$ and a polydispersity index (PDI) of 0.245 . The Au NS showed a plurality of thorn-like bulges and a star-like structure. (Fig. 1)

\section{Photothermal effect of the Au NS and its conjugates}

The temperature of different concentrations of Au NS solutions, Au NS + HEC-1A solutions and Au NS + cordycepin + HEC-1A solutions were detected after 10 minutes of $808 \mathrm{~nm}$ light exposure using an infrared temperature detector (Fig. 2). The temperature of the Au NS solution increased significantly at all concentrations; the $1.2 \times 10^{11}$ particles/ml treatment showed the most significant effect. Compared with the control group, the temperature increased from $29.2^{\circ} \mathrm{C}$ to $78.1^{\circ} \mathrm{C}$. This result indicates that the Au NS prepared in this study demonstrated the LSPR phenomenon and released energy under excitation at a specific wavelength. A similar pattern of results was observed with the Au NS + HEC-1A solutions, as the temperature increased with higher concentrations of Au NS (Fig. 2). However, the temperatures with the corresponding concentration of Au NS + HEC-1A solutions were lower than those of the Au NS solutions (without HEC-1A) (Fig. 2). This may indicate the uptake of Au NS into HEC-1A cells which may have harmed the cells.

Regarding the Au NS + cordycepin + HEC-1A solutions, the temperature of each group increased by different degrees. The temperature increased when the concentration of cordycepin increased from 0.05 to $0.1 \mathrm{mg} / \mathrm{ml}$, but it decreased when the concentration of cordycepin increased from 0.1 to $0.2 \mathrm{mg} / \mathrm{ml}$. This may suggest that cordycepin induced damage to the HEC-1A cells and thus affected the uptake of the Au NS particles.

\section{Detection of Au NS uptake}

The uptake of Au NS by HEC-1A cells was detected by ultraviolet-visible spectrophotometry. The OD values of the HEC-1A mixture with Au NS at concentrations of $3 \times 10^{10}, 6 \times 10^{10}$ and $1.2 \times 10^{11}$ particles $/ \mathrm{ml}$ were $0.036,0.280$ and 0.310 , respectively. This indicates that the uptake was proportional to the concentration of Au NS. Fig. 3 shows an image of HEC-1A cells following the uptake of Au NS visualised using an inverted microscope. The OD values of $3 \times 10^{10}$ particles $/ \mathrm{ml}$ Au NS mixture with cordycepin concentrations of $0.05,0.1$ and $0.2 \mathrm{mg} / \mathrm{ml}$ were $0.103,0.261$ and 0.191 , respectively. These values are higher than those of the corresponding Au NS alone groups, which indicates that cordycepin may enhance the uptake of Au NS by HEC-1A cells. Similar to the photothermal effects of Au NS and cordycepin described above, the OD value of the $0.2 \mathrm{mg} / \mathrm{ml}$ group was lower than that of the $0.1 \mathrm{mg} / \mathrm{ml}$ group. This may be due to damage to HEC-1A cells caused by the high concentration of cordycepin and thus reduced uptake of Au NS particles. 


\section{Cytotoxicity assay}

The inhibition rates of cordycepin, Au NS and the combinations on HEC-1A were assessed using the MTT (tetrazolium) assay (Table 1). The inhibition rates caused by cordycepin were dose-dependent, i.e. inhibition rates increased with higher concentrations. The $0.4 \mathrm{mg} / \mathrm{ml}$ cordycepin solution produced an inhibition rate of over $90 \%$. Regarding Au NS, Table 1 illustrates the effects of light exposure; Au NS significantly increased the inhibition rates $(P<0.01)$. For instance, the inhibition rates at $1.2 \times 10^{11}$ particles/ml with and without light exposure were $96.9 \%$ and $9.0 \%$, respectively. The inhibition rates of both $0.4 \mathrm{mg} / \mathrm{ml}$ cordycepin and $1.2 \times 10^{11}$ Au NS particles $/ \mathrm{ml}$ were over $90 \%$. Comparing the results of $\mathrm{Au}$ NS or cordycepin alone with their combinations, the inhibitory ability of the mixture was higher (Table 1). For example, the inhibition rates of light-exposed $3.0 \times 10^{10}$ particles $/ \mathrm{ml}$ Au NS, $0.1 \mathrm{mg} / \mathrm{ml}$ cordycepin and Au NS-cordycepin $\left(3.0 \times 10^{10}\right.$ particles $\left./ \mathrm{ml}+0.1 \mathrm{mg} / \mathrm{ml}\right)$ were $2.3 \%, 46.1 \%$ and $68.7 \%$, respectively. This indicates that the combined use of Au NS and cordycepin inhibited HEC-1A cells more effectively than the individual treatments did. As with the Au NS alone solutions, the inhibition rates of the light-exposed Au NS-cordycepin solutions were significantly higher than those without light exposure $(P<0.01)$ (Table 1$)$. The inhibition rates of all the light-exposed Au NS-cordycepin solutions with an Au NS concentration of $6.0 \times 10^{10}$ particles $/ \mathrm{ml}$ or higher were at least $90 \%$. Again, this value is much higher than that with Au NS alone.

\section{Apoptosis}

The total apoptosis rate of all the different concentrations of Au NS, cordycepin and their combinations were significantly higher than that of the control samples $(P<0.01)$ (Fig. 4 and 5$)$. The rates of the experimental groups were generally dose-dependent. The apoptotic rate of the control was $5.1 \% \pm 0.4 \%$, whereas the rates at $0.05 \mathrm{mg} / \mathrm{ml}, 0.1 \mathrm{mg} / \mathrm{ml}$ and $0.2 \mathrm{mg} / \mathrm{ml}$ of cordycepin were $20.5 \%, 19.0 \%$ and $33.1 \%$, respectively. Au NS at $3.0 \times 10^{10}, 6.0 \times 10^{10}$ and $1.2 \times 10^{11}$ particles $/ \mathrm{ml}$ provided an apoptotic rate of $12.8 \%$, $21.6 \%$ and $27.5 \%$, respectively. Combined Au NS-cordycepin with light exposure achieved a higher apoptotic rate then the individual treatments (Fig. 4 and 5). For instance, the rate with the Au NScordycepin $\left(6.0 \times 10^{10}\right.$ particles $\left./ \mathrm{ml}+0.05 \mathrm{mg} / \mathrm{ml}\right)$ combination was $71.0 \%$, which was much higher rate than that of the individual treatments at the same concentrations. The rate of Au NS at $6.0 \times 10^{10}$ particles $/ \mathrm{ml}$ and cordycepin at $0.05 \mathrm{mg} / \mathrm{ml}$ were $21.6 \%$ and $20.5 \%$, respectively.

\section{Clonogenic survival assay}

Clonogenic survival assays were performed to investigate the effects of Au NS, cordycepin, and the combinations on the clonogenic ability of HEC-1A cells. Both cordycepin and Au NS with light exposure inhibited clone formation in a dose-dependent manner (Table 2). The combination increased the SF of $A u$ NS or cordycepin alone. For example, the SF of Au NS $\left(3.0 \times 10^{10}\right.$ particles $\left./ \mathrm{ml}\right)$, cordycepin $(0.1 \mathrm{mg} / \mathrm{ml})$, and Au NS-cordycepin $\left(3.0 \times 10^{10}\right.$ particles $\left./ \mathrm{ml}, 0.1 \mathrm{mg} / \mathrm{ml}\right)$ were $0.93,0.61$ and 0.01 , respectively. This indicates that the combinations induced greater clonogenic inhibition ability than each treatment alone. 
Similar to the results of the cytotoxic assay, Au NS with no light exposure did not induce significant clonogenic inhibitory effects.

\section{Discussion}

Many studies have shown the anti-cancer properties of cordycepin against various cancers, i.e. liver cancer [17], tongue cancer [18] and breast cancer [19]. The pharmacological mechanism responsible for the anticancer properties of cordycepin is thought to be activation of adenosine A3R, which can inhibit cell growth. Cordycepin can integrate with RNA and prevent transcription, elongation and RNA synthesis [20]. These effects cordycepin can effectively induce cancer cell apoptosis and reduce the potential of cancer metastasis [21]. Although cordycepin has anti-cancer properties, its clinical usage is limited. This is because of its short duration of action in the body due to metabolism by adenosine deaminase (ADA) enzymes [9]. Au NS is a star-shaped nanomaterial with a coarse surface and high surface-to-volume ratio, which allow Au NS to act as a drug carrier for anti-cancer drug delivery [22]. This property may protect cordycepin from ADA metabolism and increase the amount of cordycepin that can reach tumours. Au NS produces localised surface plasmon resonance (LSPR) when exposed to infrared light at $808 \mathrm{~nm}$. These nanoparticles have been shown to be very stable, and produce efficient photothermal effects after the absorption of laser energy [23]. This generates heat energy and kills cancer cells. Recently, researchers have investigated the use of Au NS in anti-tumour research [24]; the current study revealed the synergistic anti-endometrial cancer effects caused by Au NS and cordycepin.

\section{Conclusions}

Through the use of cytotoxic assays, clonogenic survival assays and apoptosis assessments, this study showed that both cordycepin and Au NS (photothermally excited) can effectively inhibit the proliferation of endometrial HEC-1 A cancer cells in a dose-dependent manner, with an inhibition constant $\left(\mathrm{IC}_{50}\right)$ of 0.17 $\mathrm{mg} / \mathrm{ml}$ and $6.5 \times 10^{10}$ particles $/ \mathrm{ml}$, respectively. While cordycepin was combined with Au NS, cell proliferation was inhibited more effectively, and the inhibition rate was enhanced when compared with the individual treatments. Furthermore, the apoptosis rate of the Au NS-cordycepin combination at a concentration of $6.0 \times 10^{10}$ particles $/ \mathrm{ml}$ and $0.05 \mathrm{mg} / \mathrm{ml}$ reached $71 \%$, while the apoptosis rates of the individuals treatments were only $17.8 \%$ and $21.59 \%$. Hence, the combined use of these treatments greatly increased the apoptosis rate, and may potentially be used in treating endometrial cancer. We believe that this study provides a fundamental basis for further in vivo studies on the anti-cancer effectiveness of $\mathrm{Au}$ NS-cordycepin.

\section{Abbreviations}

ADAL Adenosine deaminase; Au NS: Gold nanostars; CA: Clonogenic assays; EC: Endometrial cancer; LSPR: Localised surface plasmon resonance; OD: Optical density; PBS: Phosphate buffered saline; PE: Plating efficiency; PI: propidium iodide; SF: survival fraction; TEM: Transmission electron microscope 


\section{Declarations}

Acknowledgements

Not applicable

\section{Authors' contributions}

$\mathrm{CC}, \mathrm{KM}$ and PF wrote the manuscript, $\mathrm{CL}$ and $\mathrm{MH}$ revised it. $\mathrm{LM}, \mathrm{PF}$ and $\mathrm{CA}$ were responsible for the design of the study. $\mathrm{CC}, \mathrm{KW}, \mathrm{CL}$ and $\mathrm{MH}$ participated in the data collection, data analysis and performed the statistical analysis. LM, PF and CA contributed substantially to data interpretation. All authors have read and approved the final manuscript.

\section{Funding}

The financial support of the Macao Polytechnic Institute Research Fund (Project No: RP/ESS-04/2017) is gratefully acknowledged.

\section{Availability of data and materials}

The datasets used and/or analysed during the current study are available from the corresponding author on reasonable request.

\section{Ethics approval and consent to participate}

Not applicable.

\section{Consent for publication}

Not applicable.

\section{Competing interests}

The authors declare that they have no competing interests.

\section{References}

1. US National Cancer Institute. SEER Stat Fact Sheets: Endometrial Cancer. Retrieved from: http://seer.cancer.gov/statfacts/html/corp.html.

2. Cho KR, Cooper K, Croce S, Djordevic B, Herrington S, Howitt B, Hui P, Ip P, Koebel M, Lax S, Quade BJ, Shaw P, Vidal A, Yemelyanova A, Clarke B, Hedrick Ellenson L, Longacre TA, Shih IM, McCluggage WG, Malpica A, Oliva E, Parkash V, Matias-Guiu X. International Society of Gynecological Pathologists (ISGyP) Endometrial Cancer Project: Guidelines From the Special Techniques and Ancillary Studies Group. Int J Gynecol Pathol. 2019;38 Suppl 1:S114-22. 
3. DeSantis CE, Lin CC, Mariotto AB, Siegel RL, Stein KD, Kramer JL, Alteri R, Robbins AS, Jemal A. Cancer treatment and survivorship statistics, 2014. A CancerJ Clin. 2014;64(4):252-71.

4. Li-Weber M. Targeting apoptosis pathways in cancer by Chinese medicine. Cancer Lett. 2013;332(2):304-12.

5. Qi F, Zhao L, Zhou A, Zhang B, Li A, Wang Z, Han J. The advantages of using traditional Chinese medicine as an adjunctive therapy in the whole course of cancer treatment instead of only terminal stage of cancer. BiosciTrends. 2015;9(1):16-34.

6. Tania M, Shawon J, Saif K, Kiefer R, Khorram MS, Halim MA, Khan M. Cordycepin Downregulates Cdk-2 to Interfere with Cell Cycle and Increases Apoptosis by Generating ROS in Cervical Cancer Cells: in vitro and in silico Study. Curr Cancer Drug Targets. 2019;19(2):152-9.

7. Tao X, Ning Y, Zhao X, Pan T. The effects of cordycepin on the cell proliferation, migration and apoptosis in human lung cancer cell lines A549 and NCl-H460. J Pharm Pharmacol. 2016;68(7):90111.

8. Fong P, Ao CN, Tou KI, Huang KM, Cheong CC, Meng LR. Experimental and In Silico Analysis of Cordycepin and its Derivatives as Endometrial Cancer Treatment. Oncol Res. 2019;27(2):237-51.

9. Li G, Nakagome I, Hirono S, Itoh T, Fujiwara R. Inhibition of adenosine deaminase (ADA)-mediated metabolism of cordycepin by natural substances. Pharmacol Res Perspect. 2015;3(2):

10. Khoury CG, Vo-Dinh T. Gold nanostars for surface-enhanced Raman scattering: synthesis, characterization and optimization. J Phys Chem C. 2008;112(48):18849-59.

11. Su G, Miao D, Yu Y, Zhou M, Jiao P, Cao X, Yan B, Zhu H. Mesoporous silica-coated gold nanostars with drug payload for combined chemo-photothermal cancer therapy. J Drug Target. 2019;27(2):20110.

12. Chen H, Zhang X, Dai S, Ma Y, Cui S, Achilefu S, Gu Y. Multifunctional gold nanostar conjugates for tumor imaging and combined photothermal and chemo-therapy. Theranostics. 2013;3(9):633-49.

13. Li Y, Ma J, Ma Z. Synthesis of gold nanostars with tunable morphology and their electrochemical application for hydrogen peroxide sensing. Electrochim Acta. 2013;108:435-40.

14. Nergiz SZ, Gandra N, Tadepalli S, Singamaneni S. Multifunctional hybrid nanopatches of graphene oxide and gold nanostars for ultraefficient photothermal cancer therapy. ACS Appl Mater Interfaces. 2014;6(18):16395-402.

15. Bahuguna A, Khan I, Bajpai VK, Kang SC. MTT assay to evaluate the cytotoxic potential of a drug. Bangladesh J Pharmacol. 2017;12(2):Online: Apr 8-2017.

16. Franken NA, Rodermond HM, Stap J, Haveman J, Van Bree C. Clonogenic assay of cells in vitro. Nat. Protoc. 2006;1(5):2315.

17. Wang Z, Wu X, Liang Y, Wang L, Song Z, Liu J, Tang Z. Cordycepin induces apoptosis and inhibits proliferation of human lung cancer cell line $\mathrm{H} 1975$ via inhibiting the phosphorylation of EGFR. Molecules. 2016;21(10):1267. 
18. Zheng QW, Gao SX, Lv J, Chen DY, Chen J, Li HH, Guan JC. Effect of cordycepin on apoptosis and autophagy of tongue cancer cells in vitro and the molecular mechanism. J South Med Uni. 2018;38(4):390-4.

19. Wang D, Zhang Y, Lu J, Wang Y, Wang J, Meng Q, Lee RJ, Wang D, Teng L. Cordycepin, a natural antineoplastic agent, induces apoptosis of breast cancer cells via caspase-dependent pathways. Nat Prod Commun. 2016;11(1):1934578X1601100119.

20. Yoshikawa N, Nakamura K, Yamaguchi Y, Kagota S, Shinozuka K, Kunitomo M. Antitumour activity of cordycepin in mice. Clin Exp Pharmacol Physiol. 2004;31:S51-3.

21. Ni H, Li Y, Hao R, Li H, Hu S, Li H. Identification of adenosine deaminase inhibitors from Tofu wastewater and litchi peel and their synergistic anticancer and antibacterial activities with cordycepin. Int J Food Sci Tech. 2016;51(5):1168-76.

22. Ramos J, Taylor D, Rege K. Gold nanoparticle mediated photo-chemotherapy. J Nanomed Nanotech. 2012;3(8):9.

23. Wang S, Huang P, Nie L, Xing R, Liu D, Wang Z, Lin J, Chen S, Niu G, Lu G. Single continuous wave laser induced photodynamic/plasmonic photothermal therapy using photosensitizer-functionalized gold nanostars. Adv Mater. 2013;25(22):3055-61.

24. Park H, Lim D, Vines JB, Yoon J, Ryu N. Gold nanoparticles for photothermal cancer therapy. Front Chem. 2019;7:167.

\section{Tables}

Table 1 Inhibition rates of Au NS, cordycepin and their combinations on HEC-1A cells

\begin{tabular}{lr}
\hline Compounds (Concentration) & Inhibition rate $\%$ \\
\hline Au NS (3.0) & 8.3 \\
Au NS (6.0) & 5.2 \\
Au NS (12.0) & 9.0 \\
& \\
Au NS (3.0)* & 2.3 \\
Au NS (6.0)* & 55.4 \\
Au NS (12.0)* & 96.9 \\
& \\
Cordycepin (0.05) & 30.8 \\
Cordycepin (0.1) & 46.1 \\
Cordycepin (0.2) & 62.8 \\
Cordycepin (0.4) & 92.7 \\
& \\
Au NS (3.0) + cordycepin (0.05) & 20.9 \\
Au NS (3.0) + cordycepin (0.1) & 38.0 \\
Au NS (3.0) + cordycepin (0.2) & 74.0 \\
& \\
Au NS (3.0) + cordycepin (0.05)* & 35.7 \\
Au NS (3.0) + cordycepin (0.1)* & 68.7 \\
Au NS (3.0) + cordycepin (0.2)* & 92.2 \\
\hline
\end{tabular}

Concentration of $\mathrm{Au}$ NS and cordycepin are in $10^{10}$ particles $/ \mathrm{ml}$ and $\mathrm{mg} / \mathrm{ml}$, respectively. * indicates the solutions were exposed to $808 \mathrm{~nm}$ light for 10 minutes 
Table 2 Survival fraction on HEC-1A cells of cordycepin, Au NS, and their combinations

\begin{tabular}{lr}
\hline Compounds (concentration) & Survival fraction \\
\hline $\mathrm{Au}$ NS (3.0) & $0.92 \pm 0.04$ \\
$\mathrm{Au}$ NS (6.0) & $0.89 \pm 0.08$ \\
$\mathrm{Au}$ NS (12.0) & $0.87 \pm 0.05$ \\
$\mathrm{Au}$ NS (3.0)* & $0.93 \pm 0.01$ \\
$\mathrm{Au}$ NS (6.0)* & $0.36 \pm 0.05$ \\
$\mathrm{Au}$ NS (12.0)* & $0.00 \pm 0.00$ \\
& \\
Cordycepin (0.05) & $0.78 \pm 0.04$ \\
Cordycepin (0.1) & $0.61 \pm 0.03$ \\
Cordycepin (0.2) & $0.09 \pm 0.02$ \\
Cordycepin (0.4) & $0.00 \pm 0.00$ \\
& \\
Au NS (6.0) + cordycepin $(0.05)^{*}$ & $0.00 \pm 0.01$ \\
$\mathrm{Au}$ NS (3.0) + cordycepin $(0.1)^{*}$ & $0.01 \pm 0.01$ \\
\hline
\end{tabular}

Concentration of $\mathrm{Au} \mathrm{NS}$ and cordycepin are in $10^{10}$ particles $/ \mathrm{ml}$ and $\mathrm{mg} / \mathrm{ml}$, respectively. The values of all survival fractions are p<0.01, except Au NS (3.0), Au NS (6.0) and Au NS (12.0). * indicates the solutions were exposed to $808 \mathrm{~nm}$ light for 10 minutes

\section{Figures}

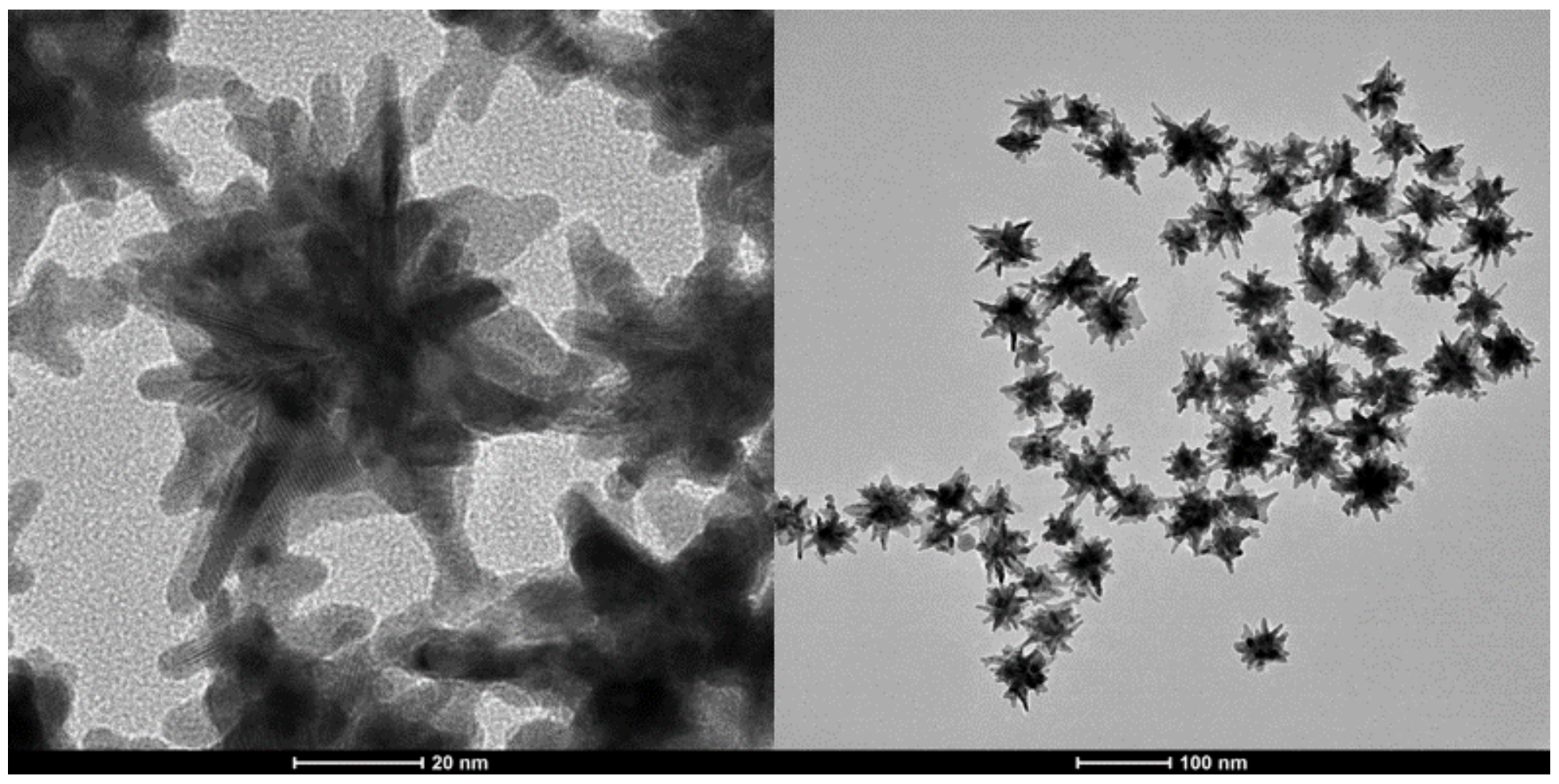

Figure 1 
Temperature ${ }^{\circ} \mathrm{C}$

Au NS (6.0) + cordycepin (0.2) + HEC-1A

Au NS (6.0) + cordycepin (0.1) + HEC-1A

Au NS (6.0) + cordycepin (0.05) + HEC-1A

Au NS (3.0) + cordycepin (0.2) + HEC-1A

Au NS (3.0) + cordycepin (0.1) + HEC-1A

Au NS (3.0) + cordycepin (0.05) + HEC-1A

$$
\begin{aligned}
& \text { Au NS (12.0) + HEC-1A } \\
& \text { Au NS (6.0) + HEC-1A }
\end{aligned}
$$

Au NS (3.0) + HEC-1A

Au NS (12.0)

Au NS (6.0)

Au NS (3.0)

Control

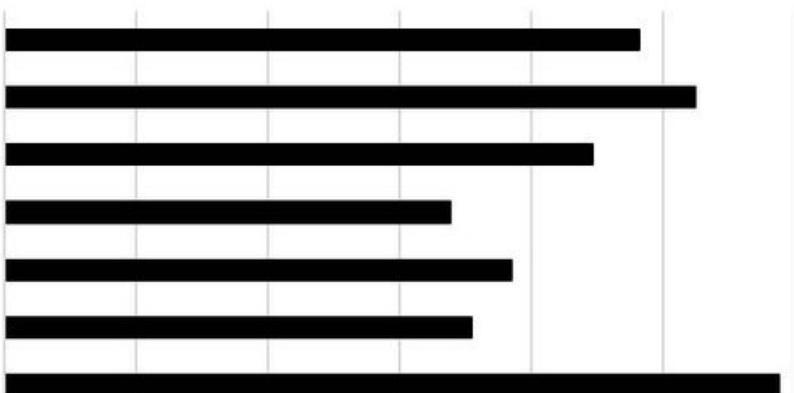

0

$10 \quad 20 \quad 30$

40

50

60

70

80

90

Figure 2

Temperature of different concentrations of Au NS solutions, Au NS + HEC-1A solutions and Au NS + cordycepin + HEC-1A solutions after 10 minutes of $808 \mathrm{~nm}$ light exposure. Concentrations of Au NS and cordycepin are 1010 particles $/ \mathrm{ml}$ and $\mathrm{mg} / \mathrm{ml}$, respectively

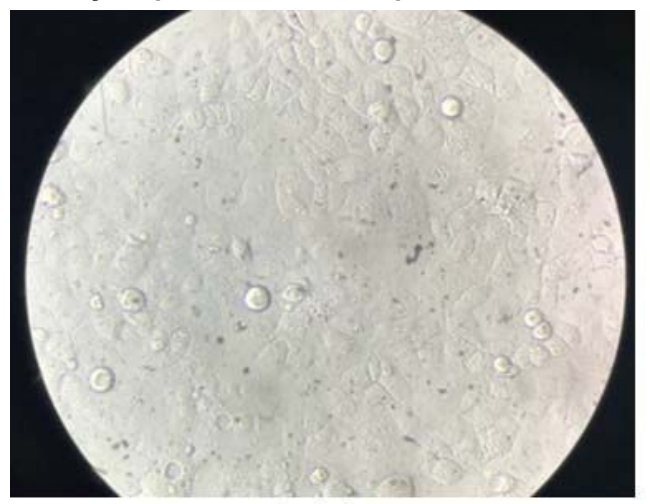

(A)

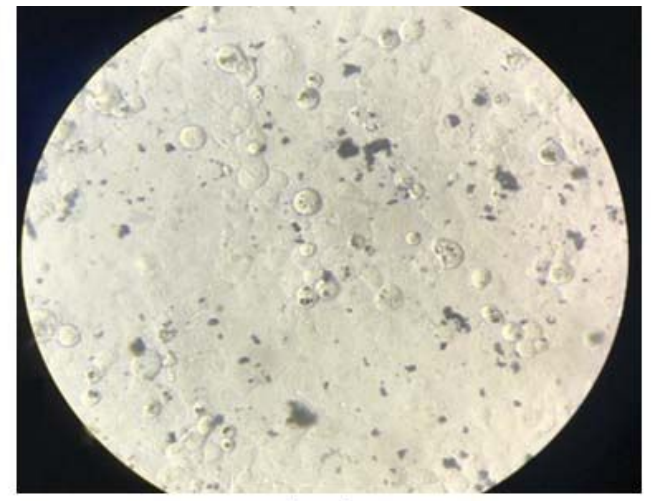

(B)

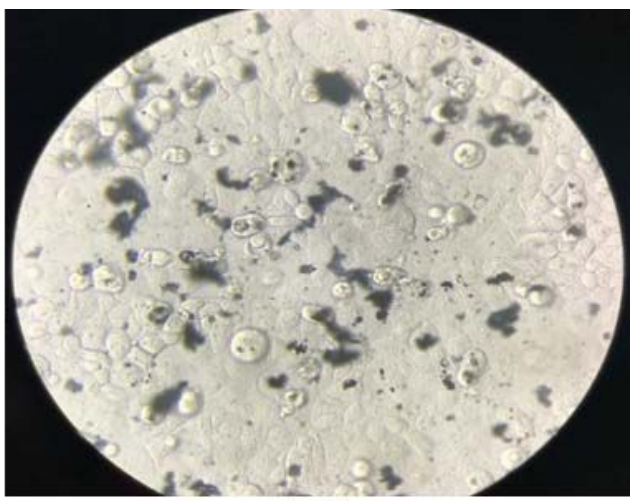

(C)

Figure 3

Uptake of Au NS by HEC-1A cells captured by an inverted microscope. The concentration of Au NS at A, B and $C$ are $3 \times 1010,6 \times 1010$ and $1.2 \times 1011$, respectively 

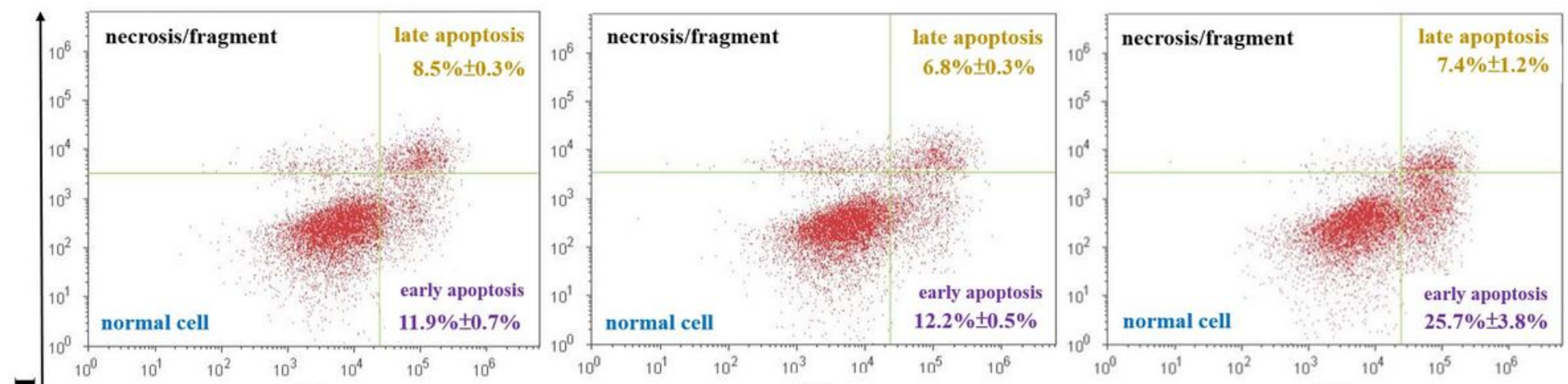

$\bar{a}$

(A)

(B)
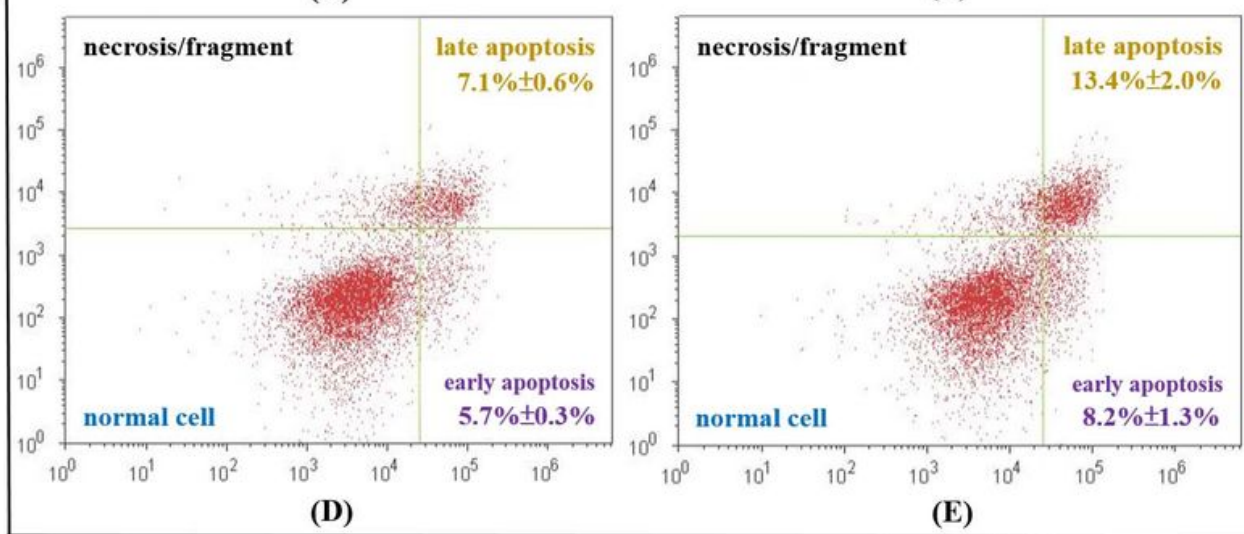

(E)

(C)

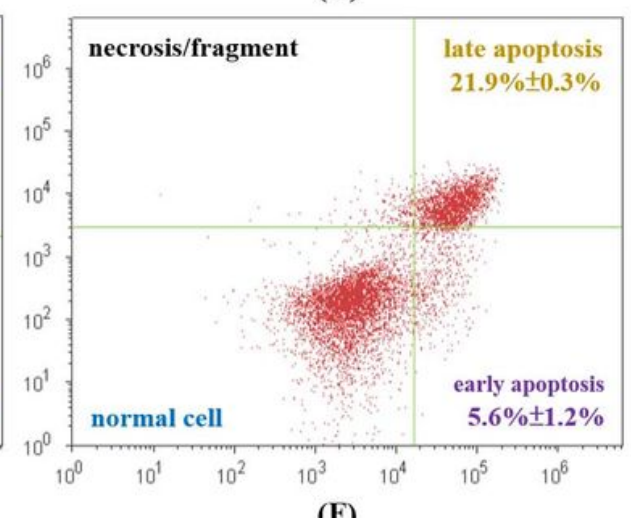

Annexvin V

\section{Figure 4}

Total rate of cellular apoptosis of HEC-1A cells caused by (A) $0.05 \mathrm{mg} / \mathrm{ml}$ of cordycepin $-20.5 \% \pm 0.7 \%$, (B) $0.1 \mathrm{mg} / \mathrm{ml}$ of cordycepin $-19.0 \% \pm 0.8 \%$, (C) $0.2 \mathrm{mg} / \mathrm{ml}$ of cordycepin $-33.1 \% \pm 5.0 \%$, (D) $3.0 \times 1010$ particles $/ \mathrm{ml}$ of Au NS $-12.8 \% \pm 0.7 \%$, (E) $6.0 \times 1010$ particles $/ \mathrm{ml}$ of Au NS $-21.6 \% \pm 0.7 \%$ and (F) $1.2 \times 1011$ particles/ml of Au NS $-27.5 \% \pm 1.4 \%$

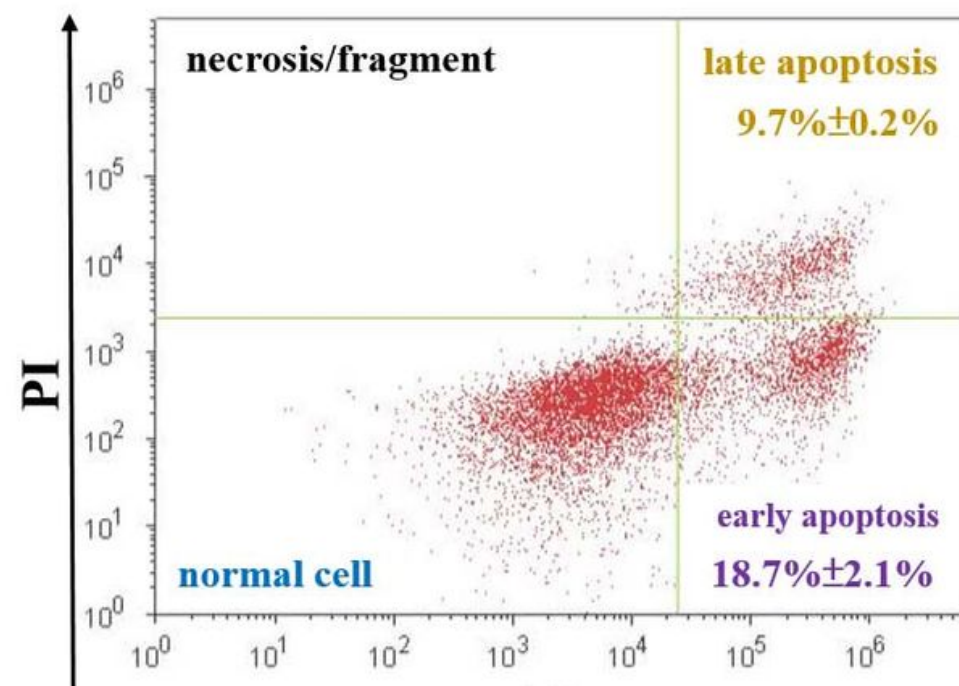

(A)

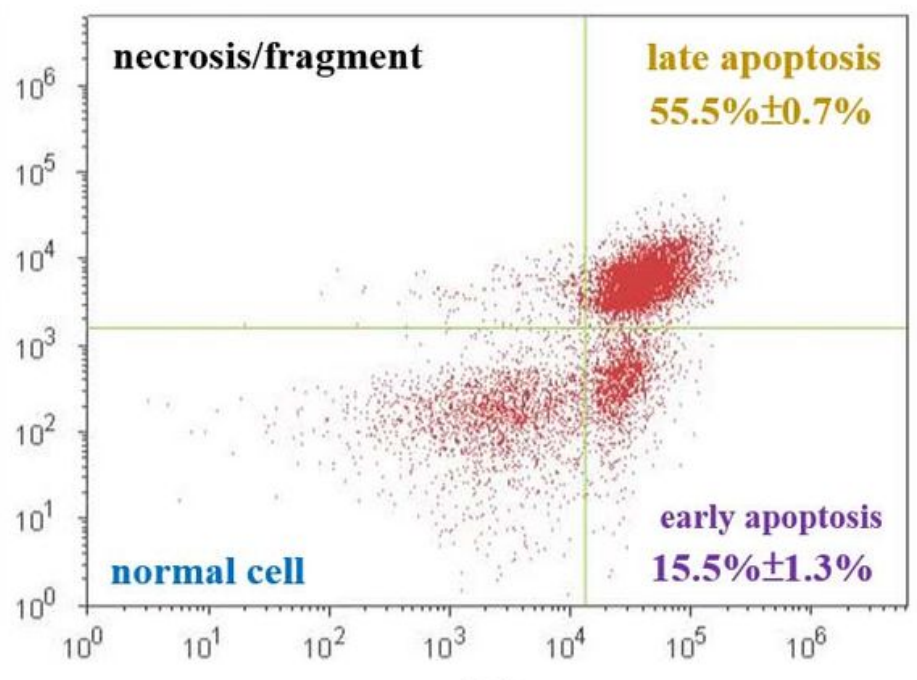

(B)

\section{Annexvin V}

\section{Figure 5}


Total rate of cellular apoptosis of HEC-1A cells caused by light exposure (A) Au NS-cordycepin (3.0x1010 particles $/ \mathrm{ml}+0.1 \mathrm{mg} / \mathrm{ml})-28.4 \% \pm 1.9 \%$ and (B) Au NS-cordycepin $(6.0 \times 1010$ particles $/ \mathrm{ml}+0.05 \mathrm{mg} / \mathrm{ml})$ $-71.0 \% \pm 1.3 \%$ 